\title{
Hypoxia-selective inhibition of angiogenesis development by NAMI-A analogues
}

\author{
Maria Oszajca • Guillaume Collet • Grażyna Stochel • Claudine Kieda • \\ Małgorzata Brindell
}

Received: 23 September 2016/ Accepted: 30 September 2016/Published online: 3 November 2016

(C) The Author(s) 2016. This article is published with open access at Springerlink.com

\begin{abstract}
The antimetastatic ruthenium(III) complex $\left(\mathrm{H}_{2} \mathrm{Im}\right)\left[\right.$ trans- $\left.\mathrm{RuCl}_{4}(\mathrm{HIm})(\mathrm{DMSO})\right]$ (NAMI-A) as well as its two analogues $\left(\mathrm{H}_{2}\right.$ Ind $)$ [trans- $\mathrm{RuCl}_{4}$ (HInd)(DMSO)] (Ru-Ind) and (HIsq) $\left[\right.$ trans- $\mathrm{RuCl}_{4}$ (Isq)(DMSO)] (Ru-Isq) (HIm-imidazole, HInd-indazole, Isq-isoquinoline, DMSO-dimethyl sulfoxide) were tested for their effect on endothelial cell functions in vitro on human skin microvascular endothelial cells (HSkMEC) and human endothelial progenitor cells (HPEC-CB.2) under normoxic $\left(21 \% \mathrm{O}_{2}\right)$ and hypoxic $\left(1 \% \mathrm{O}_{2}\right)$ conditions. All studied complexes showed very low cytotoxicity profiles towards both mature microvascular and precursor endothelial cells
\end{abstract}

Electronic supplementary material The online version of this article (doi:10.1007/s10534-016-9974-9) contains supplementary material, which is available to authorized users.

M. Oszajca $(\bowtie) \cdot$ G. Stochel · M. Brindell

Faculty of Chemistry, Jagiellonian University, Ingardena 3, 30-060 Kraków, Poland

e-mail: maria.oszajca@chemia.uj.edu.pl

G. Collet · C. Kieda ( $\square)$

Centre for Molecular Biophysics, Cell Recognition and Glycobiology, UPR4301-CNRS, rue Charles Sadron, 45071 Orléans, France

e-mail: claudine.kieda@cnrs-orleans.fr

C. Kieda

Malopolska Biotechnology Centre, Jagiellonian

University, Kraków, Poland
(ECs), independently of oxygen concentration. Among tested compounds Ru-Ind exhibited the highest cytotoxicity. The antiangiogenic activity of ruthenium complexes was evaluated for their influence on pseudo-vessels formation by microvascular endothelial cells (HSkMEC) because of their involvement in melanoma progression. Our studies indicated that $\mathrm{Ru}-$ Ind and Ru-Isq exhibited hypoxia- and dose-dependent-inhibition of angiogenesis on Matrigel $^{\mathrm{TM}}$. Significant hypoxia-selective downregulation of pseudovessels formation by $\mathrm{Ru}$-Isq correlates with efficient inhibition of cell motility. Interestingly, in the applied concentration doses migration of endothelial cells was also inhibited by NAMI-A, but the pseudo-vessels formation on Matrigel ${ }^{\mathrm{TM}}$ was unaffected. Angiogenesis-related genes expression profile for both mature and precursor ECs indicated that inhibition of angiogenesis, mainly due to Ru-Isq, as compared to NAMI$\mathrm{A}$ and Ru-Ind correlated with downregulation of CD31 and CD144 expression and upregulation of NOTCH4 expression in mature ECs, which is essential for endothelial cell motility and stalk cells organization control. The hypoxia-selective antiangiogenic activity of $\mathrm{Ru}-$ Ind and Ru-Isq, NAMI-A analogues makes them potent antimetastatic therapeutics for their selective action in hypoxia which controls tumor pathologic angiogenesis.

Keywords Ruthenium complexes - NAMI-A analogues · Angiogenesis · Hypoxia · Endothelial cells 


\section{Introduction}

Angiogenesis is a crucial step for tumor growth, supplying tumor cells with oxygen, nutrients and allowing metastasis. Cancer tissues are characterized by hypoxic areas (areas with $\mathrm{O}_{2}$ tensions $<10 \mathrm{mmHg}$ ) which arise from restricted oxygen supply due to inefficient blood vessel formation in fast growing neoplastic tissues. Hypoxia is a typical property of locally advanced solid tumors and stem cell niches. It has been estimated that 50-60\% of malignancies exhibit chronic hypoxic/anoxic areas (Vaupel and Mayer 2007). Secondary tumors often have even poorer oxygenation level than primary tumors (Höckel and Vaupel 2001). Therefore, it is of great importance to carry out in vitro experiments not only under normoxia but also under hypoxia conditions.

Tumor angiogenesis is a complex process of reaction to hypoxia and results in the formation of incomplete, leaky, permeable vessels, inefficiently supplying oxygen and nutrients to tumors cells (Kieda et al. 2013). Generally, the vicinal endothelial cells are recruited for progressing angiogenesis. However, there is more and more evidence that the mobilization of circulating endothelial progenitor like cells (EPCs) also takes place, resulting in improved neovascularization (Asahara et al. 1997). To follow this finding the evaluation of the effect of the studied compounds on angiogenesis was performed using human skin mature microvascular endothelial cell line (HSkMEC) (Kieda et al. 2002) and a human progenitor endothelial cell line (HPEC-CB.2) (Collet et al. 2016; Paprocka et al. 2011).

The aim of the present study was to assess the antiangiogenic activity of the antimetastatic ruthenium(III) complex $\quad\left(\mathrm{H}_{2} \mathrm{Im}\right)\left[\right.$ trans $-\mathrm{RuCl}_{4}(\mathrm{HIm})$ (DMSO)] (NAMI-A) as well as its two analogues ( $\mathrm{H}_{2}$ Ind)[trans- $\mathrm{RuCl}_{4}$ (HInd)(DMSO)] (Ru-Ind) and (HIsq)[trans- $\mathrm{RuCl}_{4}$ (Isq)(DMSO)] (Ru-Isq) (HIm-imidazole, HInd-indazole, Isq-isoquinoline, DMSOdimethyl sulfoxide) (Fig. 1) and decipher their role in biologically relevant conditions such as hypoxia, which exists in tumor proangiogenic sites. This also included comparing the activity on precursor endothelial cells with activity on mature endothelial cells that mimic the in vivo angiogenic process as well as angiogenesis control in tip cells with respect to stalk forming cells. To date only NAMI-A complex was evaluated in terms of its influence on angiogenesis in in vitro and in vivo studies (Bergamo and Sava 2015). It was found that NAMI-A can control angiogenesis most likely due to scavenging of NO produced by endothelial cells (ECs). The antiangiogenic effect of NAMI-A is related to inhibition of the MEK/ERK signaling pathway, downregulation of C-MYC gene expression and endothelial cell proliferation (Morbidelli et al. 2003; Pintus et al. 2002; Vacca et al. 2002).

In this study the impact of ruthenium complexes on angiogenesis is assessed by detection of pseudovessels formation as well as changes in cell migration of mature microvascular ECs. To investigate the induction and regulation of angiogenesis genes after the $\mathrm{Ru}$ complexes treatment, comparison of mRNA expression of a set of angiogenesis related genes for the ECs, both mature microvascular and precursor was performed, which allows to shed more light on the mechanisms of activity on these two types of cells. Importantly, we report for the first time the effect of NAMI-A and its two analogues (Ru-Ind and Ru-Isq) on angiogenesis of ECs under biologically relevant hypoxic conditions. Comparison of the results obtained in normoxia and hypoxia demonstrated the hypoxia-selective inhibition of angiogenesis by $\mathrm{Ru}-$ Ind and Ru-Isq. The revealed hypoxia-selective angiostatic properties of Ru-Ind and Ru-Isq makes these complexes candidates for further detailed investigation in view of medical applications.

\section{Materials and methods}

Ruthenium complexes

All chemicals used in this study were of analytical reagent grade. All three complexes $\left(\mathrm{H}_{2} \mathrm{Im}\right)[$ trans$\left.\mathrm{RuCl}_{4}(\mathrm{HIm})(\mathrm{DMSO})\right], \quad\left(\mathrm{H}_{2} \mathrm{Ind}\right)\left[\right.$ trans $-\mathrm{RuCl}_{4}$ (HInd) (DMSO)] and (HIsq)[trans- $\mathrm{RuCl}_{4}$ (Isq)(DMSO)] were prepared following the published procedure (Capozzi et al. 1998; Mestroni et al. 1998; Reisner et al. 2004), and their purity was confirmed by elemental analyses. $\left(\mathrm{H}_{2} \mathrm{Im}\right)\left[\right.$ trans $\left.-\mathrm{RuCl}_{4}(\mathrm{HIm})(\mathrm{DMSO})\right] \%$ : C, 20.97; H, 3.30; N, 12.23. Found, \%: C, 21.31; H, 3.33; N, 12.28; ( $\mathrm{H}_{2}$ Ind)[trans $-\mathrm{RuCl}_{4}$ (HInd)(DMSO)] \%: C, 34.42; H, 3.43; N, 10.04. Found, \%: C, 34.53; H, 3.42; N, 10.06; (HIsq)[trans-RuCl Ru $_{4}$ Isq)(DMSO)] \%: C, 41.39; H, 3.65; N, 4.83. Found, \%: C, 41.48; H, 3.61; N, 4.66. Ruthenium complexes were dissolved in water (except 
Fig. 1 Complexes studied in this work NAMI-A, RuInd and Ru-Isq

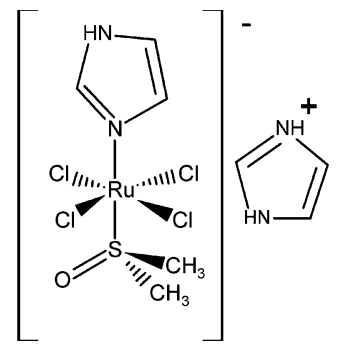

NAMI-A

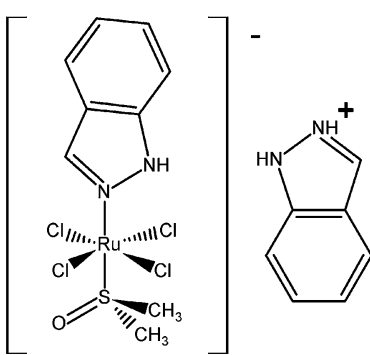

Ru-Ind

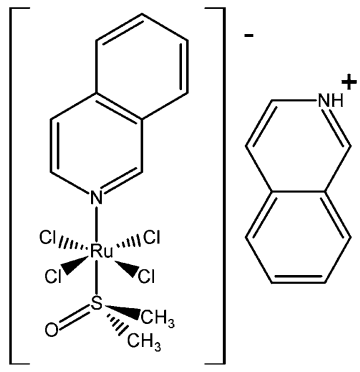

Ru-Isq for (HIsq)[trans- $\left.\mathrm{RuCl}_{4}(\mathrm{Isq})(\mathrm{DMSO})\right]$ ) and diluted to appropriate concentration in medium without serum or in complete medium with $2 \%$ serum immediately before use. (HIsq)[trans- $\mathrm{RuCl}_{4}$ (Isq)(DMSO)] was dissolved in DMSO due to poor water solubility and diluted in medium without serum and in complete medium with $2 \%$ serum (final DMSO concentration was kept constant at $0.5 \% \mathrm{v} / \mathrm{v}$ for cytotoxicity study and $0.1 \% \mathrm{v} / \mathrm{v}$ for all other experiments) just before cells treatment.

\section{Cell lines}

Two immortalized cell lines were used in this study: HSkMEC (Kieda et al. 2002)-human skin microvascular endothelial cells and HPEC-CB.2-human progenitor endothelial cells (Collet et al. 2016; Paprocka et al. 2011). Cells were cultured in OptiMEM with Glutamax (Invitrogen, Cergy Pontoise, France), supplemented with: $0.4 \%$ (w/v) gentamicin (Invitrogen), $0.2 \%$ fungizone (Invitrogen), $2 \%(\mathrm{v} / \mathrm{v})$ fetal bovine serum (BioWest, Nuaille, France). Cells were routinely maintained at $37{ }^{\circ} \mathrm{C}$ in a humidified incubator in a $5 \% \mathrm{CO}_{2} / 95 \%$ air atmosphere.

In vitro cytotoxicity evaluation

Cells (HSkMEC and HPEC-CB.2) were seeded $\left(1 \times 10^{4}\right.$ cells per $\left.\mathrm{cm}^{2}\right)$ on 96 -well cell culture plates in culture medium and grown for $24 \mathrm{~h}$ in a humidified incubator in a $5 \% \mathrm{CO}_{2} / 95 \%$ air atmosphere at $37{ }^{\circ} \mathrm{C}$. Cells were then incubated for 24 and $48 \mathrm{~h}$ in normoxic or hypoxic conditions with the tested compounds in medium without serum and in complete medium with $2 \%$ serum. For hypoxia treatment, cells were placed in a humidified atmosphere containing $1 \% \mathrm{O}_{2}, 94 \%$ $\mathrm{N}_{2}$ and $5 \% \mathrm{CO}_{2}$ gas mixture, $37{ }^{\circ} \mathrm{C}$ in a hypoxic station Whitley H35. For the treatment at hypoxic conditions, medium was conditioned at hypoxic chamber for $24 \mathrm{~h}$ before use. At the end of incubation time, ruthenium compound solutions were removed and replaced with Alamar Blue ${ }^{\mathrm{TM}}$ dye (Biosource, Nivelles, Belgium) and incubated for $3 \mathrm{~h}$ at $37{ }^{\circ} \mathrm{C}$. Fluorescence was measured at $605 \mathrm{~nm}$ (excitation wavelength $560 \mathrm{~nm}$ ) with the application of VICTOR $3 \mathrm{~V}$ multilabel plate reader from PerkinElmer.

\section{Angiogenesis assay}

Cells (HSkMEC) were seeded at the density of $2 \times 10^{4}$ cells per $\mathrm{cm}^{2}$ in a complete medium with $2 \%$ of serum. The studied compounds prepared in a medium without serum were added to the cell cultures $24 \mathrm{~h}$ after seeding and were later incubated for $24 \mathrm{~h}$ in normoxic and hypoxic conditions. Angiogenesis assay was performed on 96-well plates coated with Matrigel $^{\mathrm{TM}}$ (BD Biosciences, Grenoble, France). Cells were treated with trypsin and seeded $5 \times 10^{4}$ cells per $\mathrm{cm}^{2}$ in the presence of the tested compounds in medium without serum. The real-time visualization of the pseudo vessels formation was monitored during $24 \mathrm{~h}$ under normoxic and hypoxic conditions $\left(1 \% \mathrm{O}_{2}\right.$, $94 \% \mathrm{~N}_{2}$ and $5 \% \mathrm{CO}_{2}$ gas mixture, $37{ }^{\circ} \mathrm{C}$ ). The AxioVert $200 \mathrm{M}$ videomicroscope (Carl Zeiss) equipped with temperature, gas and humidity controllers was used to acquire images in time lapse conditions. Angiogenesis was evaluated based on the formation of pseudo-vessels on Matrigel ${ }^{\mathrm{TM}}$.

\section{Migration assay}

Cells (HSkMEC) were seeded at $2 \times 10^{4}$ cells per $\mathrm{cm}^{2}$ in a complete medium with $2 \%$ of serum. The influence of complexes on cells motility was tested on 
uncoated, plasma treated plastic plates. The studied compounds prepared in a medium without serum were added to the cell cultures $24 \mathrm{~h}$ after their seeding and incubation was allowed for $24 \mathrm{~h}$ in normoxic and hypoxic conditions. Confluent cell surface was scratched with $200 \mu \mathrm{l}$ tip. Culture medium was removed and replaced by fresh medium containing the studied compounds at the dose of $100 \mu \mathrm{M}$. Images were captured using the AxioVert $200 \mathrm{M}$ microscope (Carl Zeiss) at the beginning of the experiment and at regular intervals during cell migration to close the scratch.

Influence of the studied compounds on gene expression

Cells (HSkMEC, HPEC-BC.2) were seeded at $2 \times 10^{4}$ cells per $\mathrm{cm}^{2}$ in a complete medium with $2 \%$ of serum. The studied compounds prepared in medium without serum were added to cell cultures $24 \mathrm{~h}$ after seeding followed by $24 \mathrm{~h}$ incubation in normoxic and hypoxic conditions. mRNA was extracted from these cells using RNeasy Plus Mini kit (Qiagen). mRNA concentration and quality was checked using NanoDrop spectrophotometer ND-1000 (NanoDrop Technologies, Wilmington, DE, USA). Reverse transcription was performed with the application of "Maxima First Strand cDNA Synthesis Kit" (Fermentas). Real-time PCR was performed using SYBRGreen Premix Ex Taq (Takara Bio Inc.). HPRT1 was used as housekeeping gene (HKG).

\section{Statistical analysis}

Reported values are given as mean $\pm \mathrm{SD}$. Data are represented as averages of three biological replicates, performed in duplicate or triplicate. Statistical analyses were performed using the Student's t test with $\mathrm{p}<0.05$ considered statistically significant.

\section{Results and discussion}

Cytotoxicity assay of Ru complexes

Cytotoxicity of the studied ruthenium complexes was assessed under normoxic and hypoxic conditions after 24 and $48 \mathrm{~h}$ of incubation. The studied ruthenium complexes were screened for their ability to reduce viability of two endothelial cell lines: HSkMEC and HPEC-CB.2. In the applied concentration range $(1.5-200 \mu \mathrm{M})$ for each of the compounds only $\mathrm{Ru}-$ Ind reduced HSkMEC viability at a concentration higher than $100 \mu \mathrm{M}$. This occurred both in normoxia and hypoxia when compound was administered in medium without serum (Figs. 2, Suplementary Material Fig. S1). In medium with serum, the effect on endothelial cells was slightly less pronounced under both normoxic and hypoxic conditions (Suplementary Material Fig. S1). Two other ruthenium complexes, NAMI-A and Ru-Isq did not inhibit the growth of HSkMEC at dose up to $200 \mu \mathrm{M}$ (Figs. 2, Suplementary Material Fig. S1). However, it was shown that in human umbilical vein endothelial cells (HUVEC), which are commonly used but are macrovascular ECs, the NAMI-A complex becomes cytotoxic in concentration above $100 \mu \mathrm{M}$ (Vacca et al. 2002), indicating cell-type specific effects of this compound.

A very similar cytotoxicity profile was obtained for HPEC-CB. 2 cell line. Analogically, NAMI-A showed no cytotoxic effect up to $200 \mu \mathrm{M}$ concentration, whereas only slightly pronounced effect of Ru-ISQ was observed for the highest studied dose, $200 \mu \mathrm{M}$, under normoxic and hypoxic conditions (Suplementary Material Fig. S2). Ru-Ind showed the strongest viability inhibition, with $\mathrm{IC}_{50}$ between 100 and 200 $\mu \mathrm{M}$ (Suplementary Material Fig. S2). Comparison of cytotoxicity profiles indicates a slightly higher sensitivity of HPEC-CB.2 than HSkMEC to the studied ruthenium complexes.

The obtained results revealed that, neither duration of the treatment nor oxygen availability (hypoxia vs. normoxia) had a significant influence on their viability in the presence of the ruthenium complexes. However, a meaningful difference was observed between experiments in medium with and without serum for cytotoxic doses of Ru-Ind. Thus the decreased activity of the complex may arise from the formation of ruthenium-protein adducts (Bergamo et al. 2003; Mazuryk et al. 2012; Timerbaev et al. 2006).

The observed higher cytotoxicity of Ru-Ind than NAMI-A in endothelial cell lines is in agreement with cytotoxicity profile for these complexes reported by Groessl et al. (2007) showing rather moderate cytotoxicity of these two ruthenium complexes, with $\mathrm{IC}_{50}$ above $170 \mu \mathrm{M}$ in human tumor cell lines. Higher sensitivity of tumor cell lines to Ru-Ind than NAMI-A or Ru-Isq might arise from its hydrolytic behavior, 


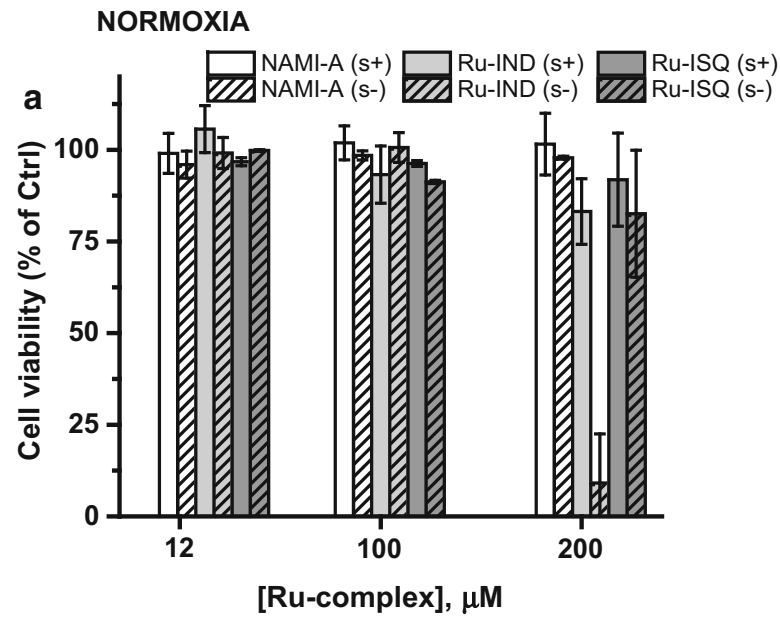

Fig. 2 Cytotoxic effect of studied compounds on HSkMEC under normoxic (a) and hypoxic (b) conditions, NAMI-A$\left(\mathrm{H}_{2} \mathrm{Im}\right)\left[\right.$ trans $\left.-\mathrm{RuCl}_{4}(\mathrm{HIm})(\mathrm{DMSO})\right]$, Ru-Isq-(HIsq) trans- $\mathrm{RuCl}_{4}$ (Isq)(DMSO)], Ru-Ind-( $\mathrm{H}_{2}$ Ind)[trans- $\mathrm{RuCl}_{4}$ (HInd)(DMSO)] in

which pointed to the complete dissociation of N-heterocyclic ligand under physiological like condition (Oszajca et al. 2016). In contrast, only ca. $30 \%$ of isoquinoline dissociated from $\mathrm{Ru}-\mathrm{Isq}$, while no release of imidazole was observed for NAMI-A (Oszajca et al. 2016).

However, the observed cytotoxicity profile for $\mathrm{Ru}$ Ind and Ru-Isq is in contrast to the results reported for very similar complexes bearing more lipophilic TMSO ligand instead of DMSO namely, $\mathrm{Na}$ [trans$\mathrm{RuCl}_{4}$ (Isq)(TMSO)] and $\mathrm{Na}\left[\right.$ trans- $\mathrm{RuCl}_{4}$ (HInd) (TMSO)] (TMSO-tetramethylsulfoxide). Capozzi et al. (1998) reported that $\mathrm{Na}\left[\right.$ trans $-\mathrm{RuCl}_{4}$ (Isq) (TMSO)] is much more cytotoxic than $\mathrm{Na}$ trans$\mathrm{RuCl}_{4}$ (HInd)(TMSO)] on TLX5 lymphoma, comparably to cisplatin. This is in contrast with our results showing that Ru-Isq is devoid of any detectable cytotoxic effect on HSkMEC in the studied concentration range similar to the used concentration of NAMI-A, whereas Ru-Ind displayed a significant cytotoxic effect only at higher doses when administered in medium without serum. Much higher cytotoxic effect of $\mathrm{Na}$ [trans $-\mathrm{RuCl}_{4}$ (Isq)(TMSO)] and $\mathrm{Na}$ [trans$\mathrm{RuCl}_{4}$ (HInd)(TMSO)] was observed on a cancer cell line, when compared with analogues studied by us on endothelial cells. This seems to be related to the presence of TMSO ligand which provides higher lipophilicity of the complexes. This in turn may favor a cellular uptake and result in a more significant effect

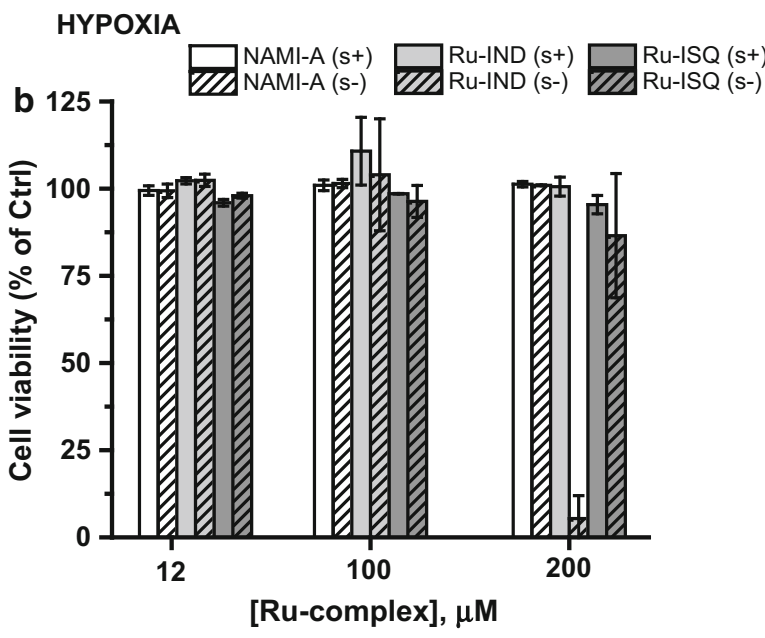

medium with serum (s+) and without serum (s-) after $24 \mathrm{~h}$ of incubation. Values are mean $\pm \mathrm{SD}$ of the three independent experiments

on cell viability. Furthermore, these results also stress that the strength of coordination of $\mathrm{N}$-heterocyclic ligand to ruthenium ion plays a major role in the cytotoxic effect of studied complexes.

The absence of a lethal effect of the studied Ru-Ind and Ru-Isq up to high doses (similarly to NAMI-A) on endothelial cell lines indicates the pharmacological potency of the selected ruthenium complexes and encourages further study of their influence on angiogenesis development.

Angiogenesis assay

Since it has been already shown that antimetastatic activity of NAMI-A may be antiangiogenic-dependent (Morbidelli et al. 2003; Vacca et al. 2002), we decided to test antiangiogenic properties of the selected NAMI-A analogues and compare their activity with NAMI-A. The antiangiogenic activity of the ruthenium complexes was evaluated by the formation of pseudo-vessels on Matrigel ${ }^{\mathrm{TM}}$ by HSkMEC. The estimation of the influence of studied complexes on angiogenesis development by HPEC-CB. 2 failed due to their limited capability to form angiogenetic network and a related inability to properly quantify the observed effect.

Since pseudo-vessel formation occurs much faster under hypoxic conditions, quantification of experimental data was performed after $7 \mathrm{~h}$ for hypoxic and 
$11 \mathrm{~h}$ for normoxic conditions. Influence of the studied ruthenium complexes on neovascularization was evaluated by comparison of two relevant descriptor variables: the number of formed pseudo-vessels and their mean length. Results of the representative data are shown in Table 1. Surprisingly, after the treatment with NAMI-A, only a slight effect on pseudo-vessel mean length was observed in both hypoxia and normoxia. This finding is in contrast to the results reported by Vacca et al. (2002) who showed a dosedependent anti-angiogenic activity in the chorioallantoic membrane model. A more pronounced effect on angiogenesis development was observed after treatment with Ru-Ind and Ru-Isq, though hypoxic conditions significantly strengthened the anti-angiogenic activity when compared with normoxia. In normoxia only the pseudo-vessels mean length was suppressed in a dose-dependent manner, whereas the number of vessels was unaffected by ruthenium complexes
(Table 1, see also Fig. 3). In contrast, both NAMI-A analogues exhibited concentration dependent diminishing of both vessel number and vessel mean length under hypoxic conditions. The inhibitory effect of $\mathrm{Ru}-$ Isq was slightly stronger than that of Ru-Ind ( -76 vs. $-56 \%$ for vessel number at a dose of $100 \mu \mathrm{M},-28$ vs. $-35 \%$ for vessel mean length at the same dose determined in relation to the control) (Table 1; Fig. 3). Very low cytotoxicity of the selected ruthenium complexes on HSkMEC indicates that the observed anti-angiogenic effect does not result from a cytostatic activity of Ru-Ind or Ru-Isq. The obtained results point to hypoxia-selective inhibition of angiogenesis development by Ru-Ind and Ru-Isq, which is a strongly desired property sought among ruthenium complexes studied as potential antimetastatic agents.

Bergamo et al. (2002) reported that NAMI-A type complexes bearing less basic $\mathrm{N}$-donor ligand than
Table 1 Effect of the ruthenium complexes on HSkMEC angiogenesis

\begin{tabular}{|c|c|c|c|c|}
\hline \multirow[t]{2}{*}{ Cell treatment } & \multirow{2}{*}{$\begin{array}{l}\text { Vessels number } \\
(>100 \mu \mathrm{M})\end{array}$} & \multicolumn{3}{|c|}{ Vessels mean length $(\mu \mathrm{M})$} \\
\hline & & $\%$ Control & Mean $\pm \mathrm{SD}$ & $\%$ Control \\
\hline \multicolumn{5}{|l|}{ Normoxia } \\
\hline Control & 89 & 100 & $140 \pm 67$ & 100 \\
\hline$[\mathrm{NAMI}-\mathrm{A}]=50 \mu \mathrm{M}$ & 100 & 112 & $125 \pm 65$ & 89 \\
\hline$[\mathrm{NAMI}-\mathrm{A}]=100 \mu \mathrm{M}$ & 103 & 116 & $125 \pm 64$ & 89 \\
\hline \multicolumn{5}{|l|}{ Hypoxia } \\
\hline Control & 50 & 100 & $122 \pm 69$ & 100 \\
\hline$[\mathrm{NAMI}-\mathrm{A}]=50 \mu \mathrm{M}$ & 52 & 103 & $110 \pm 55$ & 90 \\
\hline$[\mathrm{NAMI}-\mathrm{A}]=100 \mu \mathrm{M}$ & 55 & 109 & $110 \pm 56$ & 90 \\
\hline \multicolumn{5}{|l|}{ Normoxia } \\
\hline Control & 101 & 100 & $136 \pm 63$ & 100 \\
\hline$[\mathrm{Ru}-\mathrm{Ind}]=50 \mu \mathrm{M}$ & 108 & 107 & $115 \pm 45$ & 84 \\
\hline$[\mathrm{Ru}-\mathrm{Ind}]=100 \mu \mathrm{M}$ & 104 & 103 & $86 \pm 55$ & 63 \\
\hline \multicolumn{5}{|l|}{ Hypoxia } \\
\hline Control & 79 & 100 & $109 \pm 53$ & 100 \\
\hline$[\mathrm{Ru}-\mathrm{Ind}]=50 \mu \mathrm{M}$ & 63 & 80 & $94 \pm 44$ & 87 \\
\hline$[\mathrm{Ru}-\mathrm{Ind}]=100 \mu \mathrm{M}$ & 35 & 44 & $71 \pm 31$ & 65 \\
\hline \multicolumn{5}{|l|}{ Normoxia } \\
\hline Control/0.1 \% DMSO & 98 & 100 & $133 \pm 65$ & 100 \\
\hline$[\mathrm{Ru}-\mathrm{Isq}]=50 \mu \mathrm{M}$ & 137 & 139 & $122 \pm 58$ & 92 \\
\hline$[\mathrm{Ru}-\mathrm{Isq}]=100 \mu \mathrm{M}$ & 108 & 110 & $99 \pm 44$ & 74 \\
\hline \multicolumn{5}{|l|}{ Hypoxia } \\
\hline Control/0.1 \% DMSO & 65 & 100 & $97 \pm 43$ & 100 \\
\hline$[\mathrm{Ru}-\mathrm{Isq}]=50 \mu \mathrm{M}$ & 31 & 48 & $79 \pm 47$ & 82 \\
\hline$[\mathrm{Ru}-\mathrm{Isq}]=100 \mu \mathrm{M}$ & 15 & 24 & $70 \pm 25$ & 72 \\
\hline
\end{tabular}



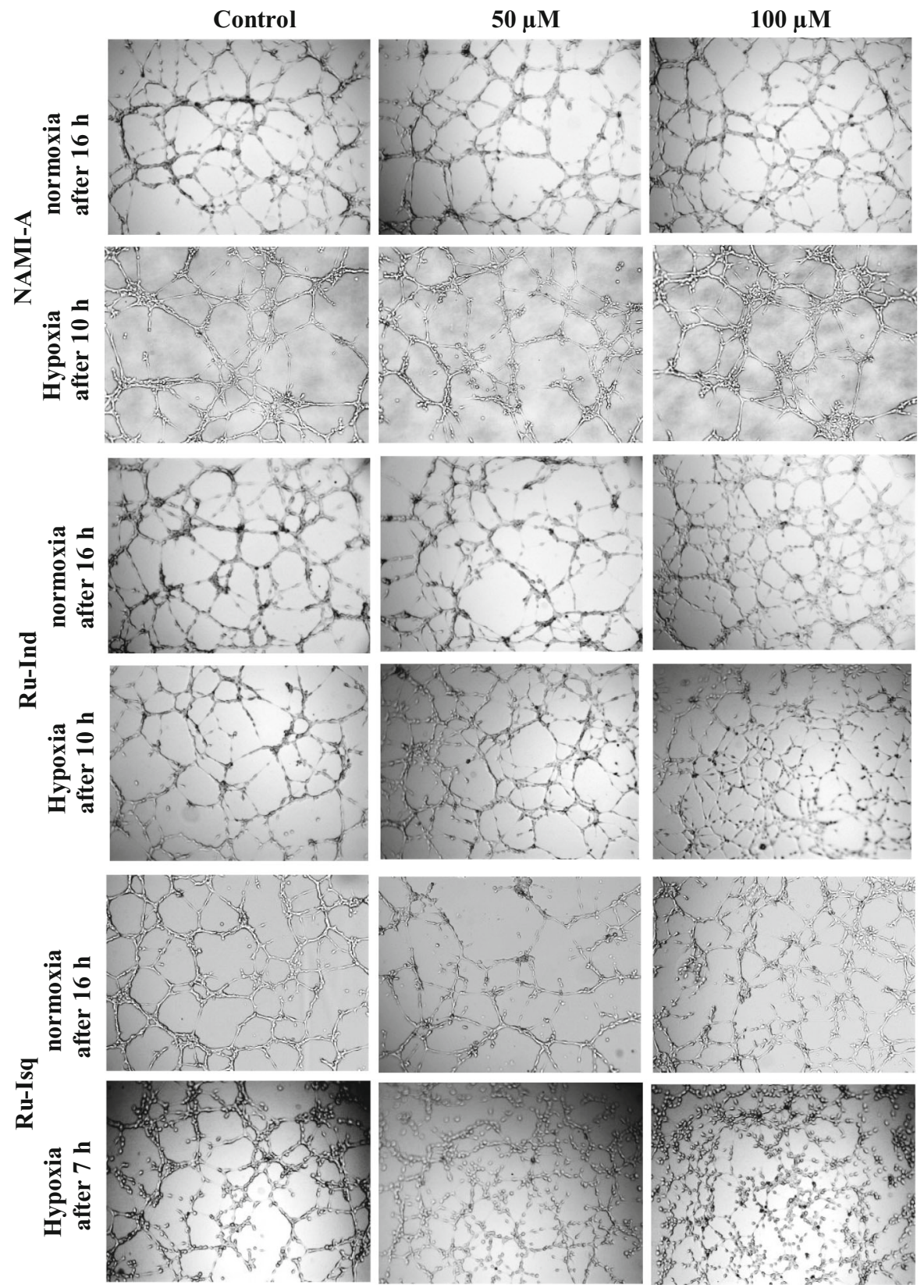

Fig. 3 Effect of the ruthenium complexes on angiogenesis by skin endothelial cells (HSkMEC) under normoxic and hypoxic conditions. HSkMEC were pre-incubated in the presence of the

imidazole display higher antitumor activity, which was assigned to reduced DMSO loss. This conclusion seems to be in line with much higher effectiveness of angiogenesis development inhibition by Ru-Ind and Ru-Isq than NAMI-A that we observed. However, comparing basicity of $\mathrm{N}$-heterocyclic ligands: ruthenium complexes (50 or $100 \mu \mathrm{M}$ ) for $24 \mathrm{~h}$, then seeded on Matrigel $^{\mathrm{TM}}$ in the presence of the same compounds

indazole $\left(\mathrm{p} K_{\mathrm{a}}=1.25\right)$ vs. isoquinoline $\left(\mathrm{p} K_{\mathrm{a}}=5.40\right)$ one could expect higher activity of Ru-Ind than RuIsq, whereas our results pointed to Ru-Isq as the most active towards angiogenesis downregulation among the studied complexes. This implies that other factors arising from different hydrolytic behavior of both 
compounds need to be considered (Oszajca et al. 2016).

\section{Migration assay}

As a second indication of activity of the ruthenium complexes on endothelial cell function, migration assays were performed using HSkMEC cells. Influence of the studied complexes on cells migration was determined $12 \mathrm{~h}$ after scratching and $36 \mathrm{~h}$ after exposure to the compounds at a dose of $100 \mu \mathrm{g} / \mathrm{ml}$. Since cellular viability was not affected at such dose after $48 \mathrm{~h}$ incubation with all the studied complexes, the observed inhibition of migration is likely to result from an anti-angiogenic activity. Among the studied complexes two of them, namely NAMI-A and Ru-Isq, significantly diminished the motility of the endothelial cells, both in normoxia and hypoxia (Fig. 4, see also Suplementary Material Fig. S3-time dependent effect of studied compounds on HSkMEC migration). Migration was $\sim 50 \%$ inhibited for Ru-Isq complex and slightly less $(\sim 35 \%)$ for NAMI-A in both normoxia and hypoxia (Fig. 3), whereas Ru-Ind was much less active under normoxic and inactive under hypoxic conditions.

The stronger influence of Ru-Isq on cell migration than two other complexes is in agreement with angiogenesis data (Table 1) and correlates well with its impact on the selected gene expression discussed in the following paragraph. Interestingly, Ru-Ind which exhibited significant effect on pseudo-vessels formation on Matrigel ${ }^{\mathrm{TM}}$ did not affect motility of the endothelial cells on uncoated, plasma treated plastic surface. In turn NAMI-A, which did not affect angiogenesis development by skin endothelial cells on Matrigel $^{\mathrm{TM}}$, revealed significant inhibiting effect on cells motility. The observed influence of the studied complexes on HSkMEC angiogenesis and motility suggests different mechanism for their activity, most probably related to the nature of the studied compounds (Oszajca et al. 2016).

Influence of the studied compounds on gene expression

To investigate the induction and regulation of angiogenesis genes after the treatment with ruthenium complexes, mRNA expression of a set of angiogenesis related genes for microvascular (HSkMEC) and progenitor (HPEC-BC.2) endothelial cell lines was determined. The expression of the following genes, with known implication in cell migration and pseudovessels formation, were analyzed: NOTCH1, NOTCH4, CD31/PECAM-1 (platelet endothelial cell adhesion molecule), CD106/VCAM-1 (vascular cell adhesion molecule 1), CD54/ICAM-1 (intercellular adhesion molecule 1), CD144/VE-cadherin (vascular endothelial cadherin). All obtained results are summarized in Figs. 5 and 6.

Among the studied complexes NAMI-A and RuInd decrease the level of NOTCH1 and NOTCH4 in HSkMEC in normoxia, whereas under hypoxia only the level of NOTCH4 expression was diminished by these two complexes. In contrast, Ru-Isq increased level of NOTCH1 and NOTCH4 in normoxia and especially in hypoxia. NOTCH proteins are
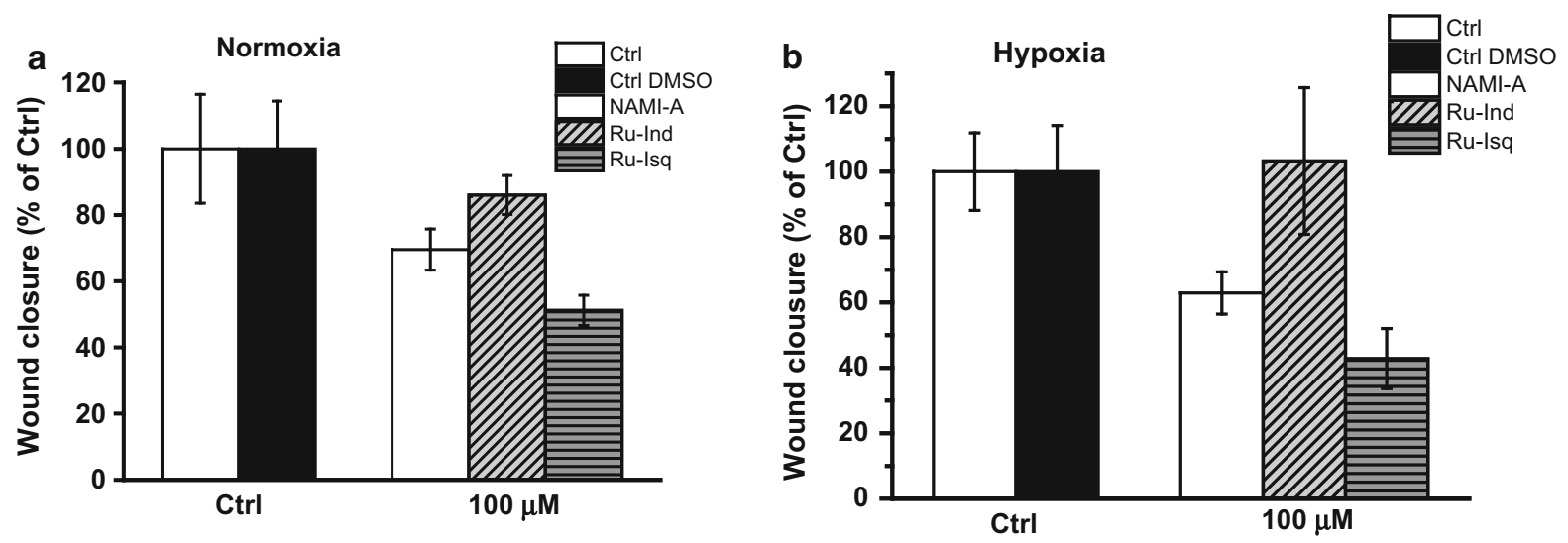

Fig. 4 Effect of the studied ruthenium complexes on skin endothelial cells (HSkMEC) motility under normoxic (a) and hypoxic (b) conditions. Quantification was done after $12 \mathrm{~h}$. Values are mean $\pm \mathrm{SD}$ 
transmembrane receptors, which play a crucial role in cells fate, differentiation as well as angiogenesis development (Artavanis-Tsakonas et al. 1999; Dufraine et al. 2008; Greenwald 1998; Milner and Bigas 1999). Both NOTCH1 and NOTCH4 receptors are expressed in vascular endothelium and regulate vascular angiogenic remodeling (Krebs et al. 2000; Uyttendaele et al. 2001). NOTCH4 controls the proper vessel structure through inhibition of the tips cells progression in favor of the stalk structure. Leong et al. (2002) reported that constitutive NOTCH4 activation in human dermal microvascular endothelial cells inhibits angiogenesis in vivo and endothelial sprout formation in vitro both spontaneously as well as in response to FGF-2 and VEGF. The ability of $\mathrm{NOTCH} 4$ to inhibit angiogenesis was ascribed to induction of active conformation of $\beta 1$-integrins, which results in promotion of adhesion (Leong et al. 2002). The significant increase in NOTCH4 expression level by Ru-Isq, especially in hypoxia is in agreement with the substantial inhibition of angiogenesis development by Ru-Isq on under hypoxia.

The influence of the ruthenium complexes on CD31 expression level in normoxia and hypoxia in HSkMEC is opposite. Under hypoxic conditions Ru-Isq diminished the level of CD31 expression, whereas under normoxic conditions this level increases. This is in contrast to the NAMI-A effect, which in hypoxia increased the expression level of this gene and slightly decreased it in normoxia. This is in agreement with the control of angiogenesis in hypoxia/normoxia as CD31 is important for vessels maturation. In the case of $\mathrm{Ru}-$

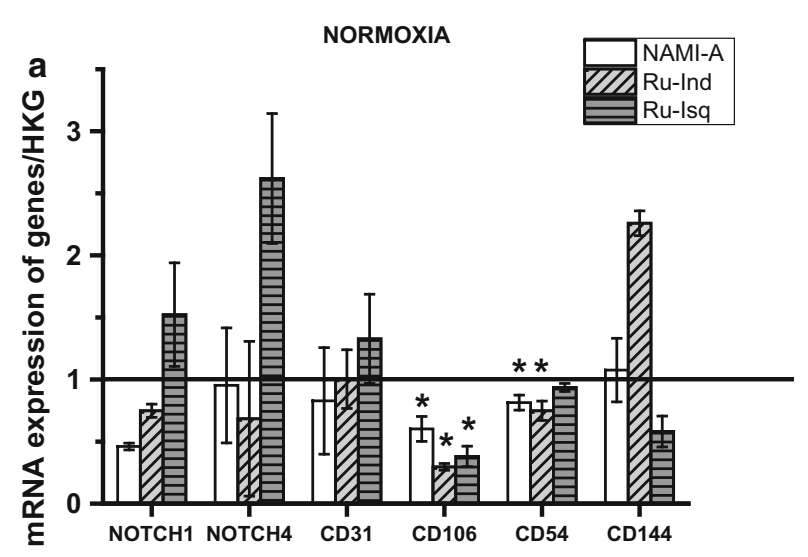

Ind no significant influence on CD31 expression in HSkMEC was observed. Interestingly, Ru-Isq also significantly diminished the expression level of the CD144 (vascular endothelial cadherin) in HSkMEC in hypoxia and normoxia. The observed decrease in the CD31 and CD144 expression levels caused by Ru-Isq, correlates with the observed destabilization of the HSkMEC pseudo-vessels network under hypoxic conditions. CD144 mediates homotypic cell adhesion and plays important role in vascular morphogenesis (Breviario et al. 1995). The significant role of CD31 in angiogenesis development has been confirmed by many studies. Carreau et al. (2011) have shown that downregulation of CD31 in HSkMEC expression correlates with the observed inhibition of pseudovessel formation by NO donors. Furthermore, earlier studies reported by Cao et al. (2002) proved that the increased expression of CD31 in cellular transfectants induced the tube formation and enhanced cell motility on Matrigel $^{\mathrm{TM}}$. Significant contrasting effect on the CD144 expression level was also observed for Ru-Ind complex, since Ru-Ind significantly upregulated the expression of this gene in both normoxia and hypoxia. In contrast the expression level of CD144 after NAMIA treatment remained almost unchanged. In normoxia all the studied complexes decreased the CD106 expression level in HSkMEC, whereas in hypoxia the same trend was observed only for NAMI-A and $\mathrm{Ru}-$ Ind. The influence of the studied ruthenium complexes on the CD54 expression level both in normoxia and hypoxia is generally similar. All of them slightly downregulate its expression except for $\mathrm{Ru}$-Isq

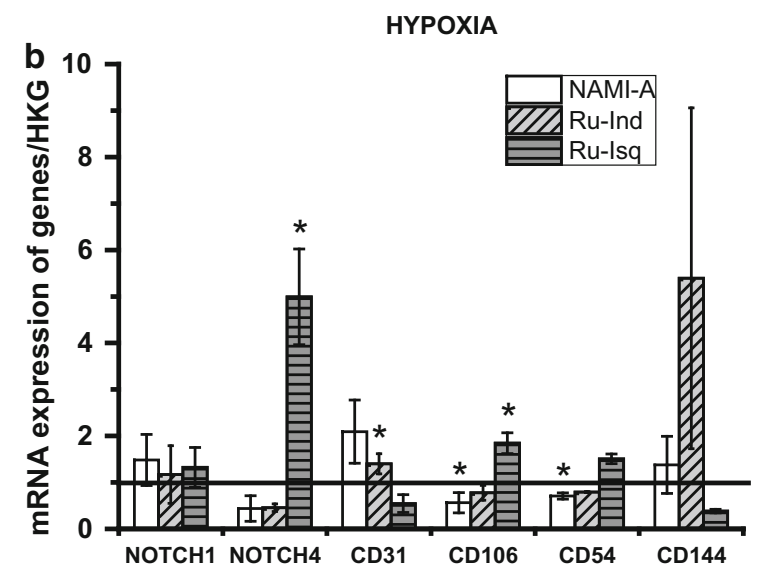

Fig. 5 Influence of the ruthenium complexes on mRNA expression in HSkMEC in normoxia (a) and hypoxia (b). Values are mean $\pm \mathrm{SD}$ of the three independent experiments, $* p<0.05$ 

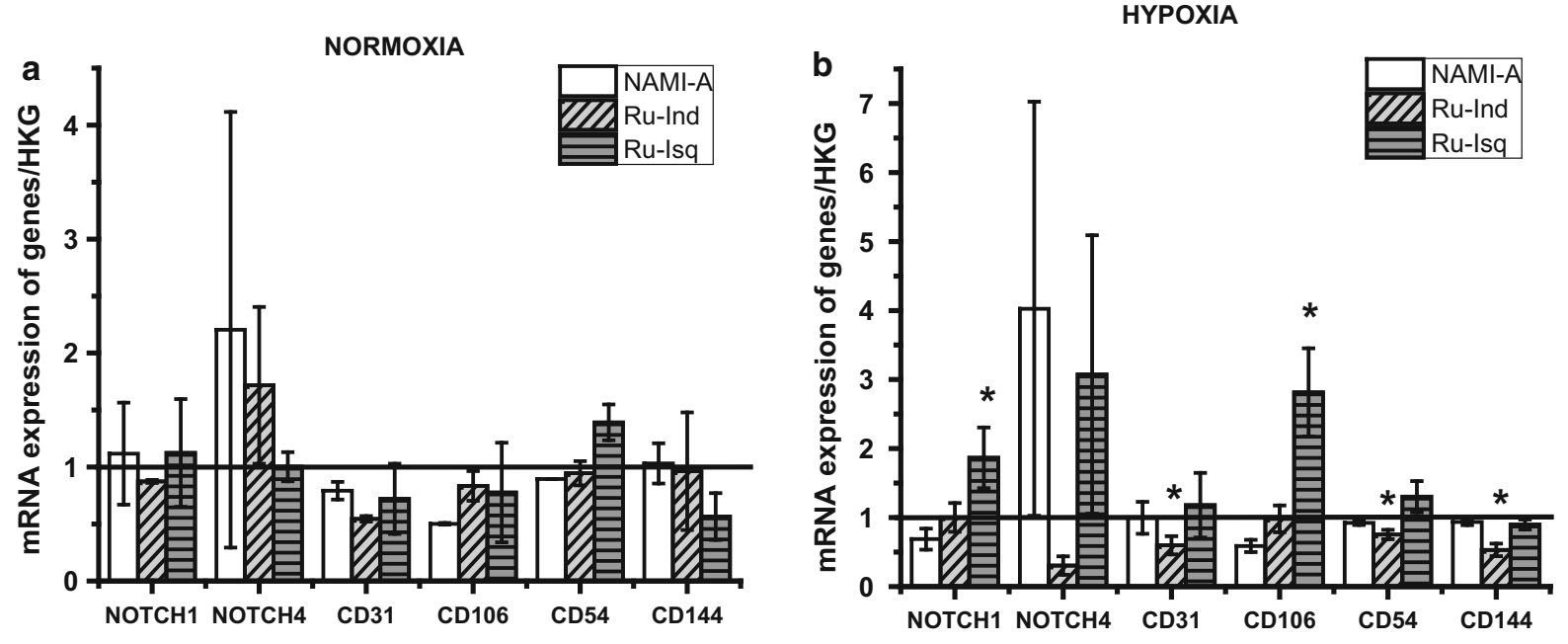

Fig. 6 Influence of studied ruthenium complexes on mRNA expression in HPEC-CB.2 in normoxia (a) and hypoxia (b). Values are mean $\pm \mathrm{SD}$ of the three independent experiments, $* p<0.05$

in hypoxia for which a slight increase in the expression of CD54 was observed.

In the case of HPEC-BC. 2 no significant modulation of the NOTCH1 by studied complexes was observed in normoxia. Under hypoxia NAMI-A downregulated NOTCH1 expression, whereas Ru-Isq upregulated it. Significant increase in the expression level of NOTCH4 was determined for NAMI-A under normoxia and hypoxia. Furthermore, NAMI-A downregulated the expression level of CD31 in normoxia as well as CD106 under normoxia and hypoxia. Influence of Ru-Ind on expression level of NOTCH4 in normoxia and hypoxia is opposite. In normoxia, upregulation of NOTCH4 was observed after Ru-Ind treatment while downregulation was displayed in hypoxia. Ru-Ind also decreased expression levels of CD31 in normoxia and hypoxia, CD106 in normoxia, as well as CD54 and CD144 in hypoxia. Similarly to NAMI-A, Ru-Isq upregulated the expression of NOTCH4 in hypoxia, however it had no influence on this gene expression in normoxia. Significant upregulating effect of Ru-Isq was also observed on CD106 but only in hypoxia. Furthermore, Ru-Isq downregulated the expression of CD31, CD106, CD144 in normoxia and slightly upregulated the expression of CD54 in normoxia and hypoxia.

Altogether, these results suggest that significant angiogenesis inhibition by Ru-Isq, which is stronger than for the other studied ruthenium complexes may be due to the molecular mechanism which leads to decreasing CD31 and CD144 expression as well as increasing NOTCH4 expression, which appear essential for EC motility and organization of pseudovessels.

\section{Conclusions}

This works brings a new view on the possibility to control angiogenesis. In this particular process it is of fundamental importance to design experimental conditions as close as possible to the biological ones. This is shown in particular by the clear differential effect exerted by the designed ruthenium complexes on the angiogenesis process in hypoxia as opposed to normoxia, as effects of the NAMI-A analogues are visible in hypoxia only.

The present work indicates that the properties of the complexes of interest could not have been evidenced in non-hypoxic conditions. This work also led to deciphering of the molecular mechanisms of the inhibitory effect on endothelial cells by pointing towards induction of NOTCH4 and its fundamental regulatory effect of the angiogenic process. Organospecificity of endothelium and the varied roles played by endothelial cells in the development of angiogenesis is reported here through the reaction of mature microvascular endothelial cells, which mimic in situ vessel sprouting during tumor development. The angiogenic properties of mature skin 
microvascular endothelial cells are inhibited by the action of Ru-Isq which was evidenced under hypoxic conditions. The second mechanism of tumor angiogenesis is recruitment of EPC mobilized from the bone marrow which was explored through the studying of the EPC line-HPEC.B2.

The use of NAMI-A analogues appears to be very promising as they are active towards the hypoxiainduced pathologic type of angiogenesis. Moreover, as their activity is exerted through NOTCH4 activation, these complexes may be able to control stalk formation and thus induce vessel normalization, which is a key mechanism to improve treatments and synergize chemotherapy and radiotherapy.

Acknowledgments This work was supported by a grant from the National Science Centre (2012/05/N/ST5/01125).

Open Access This article is distributed under the terms of the Creative Commons Attribution 4.0 International License (http:// creativecommons.org/licenses/by/4.0/), which permits unrestricted use, distribution, and reproduction in any medium, provided you give appropriate credit to the original author(s) and the source, provide a link to the Creative Commons license, and indicate if changes were made.

\section{References}

Artavanis-Tsakonas S, Rand MD, Lake RJ (1999) Notch signaling: cell fate control and signal integration in development. Science 284:770-776

Asahara T, Murohara T, Sullivan A, Silver M, van der Zee R, Li T, Witzenbichler B, Schatteman G, Isner JM (1997) Isolation of putative progenitor endothelial cells for angiogenesis. Science 275:964-967

Bergamo A, Sava G (2015) Linking the future of anticancer metal-complexes to the therapy of tumour metastases. Chem Soc Rev 44:8818-8835

Bergamo A, Gava B, Alessio E, Mestroni G, Serli B, Cocchietto M, Zorzet S, Sava G (2002) Ruthenium-based NAMI-A type complexes with in vivo selective metastasis reduction and in vitro invasion inhibition unrelated to cell cytotoxicity. Int J Oncol 21:1331-1338

Bergamo A, Messori L, Piccioli F, Cocchietto M, Sava G (2003) Biological role of adduct formation of the ruthenium(III) complex NAMI-A with serum albumin and serum transferrin. Investig New Drugs 21:401-411

Breviario F, Caveda L, Corada M, Martin-Padura I, Navarro P, Golay J, Introna M, Gulino D, Lampugnani MG, Dejana E (1995) Functional properties of human VE-cadherin (7B4/cadherin-5) an endothelial specific cadherin. Arterioscler Thromb 15:1229-1239

Cao G, O'Brien CD, Zhou Z, Sanders SM, Greenbaum JN, Makrigiannakis A, DeLisser HM (2002) Involvement of human PECAM-1 in angiogenesis and in vitro endothelial cell migration. Am J Phys Cell Phys 208:C1181-C1190

Capozzi I, Clerici K, Cocchietto M, Salerno G, Bergamo A, Sava G (1998) Modification of cell cycle and viability of TLX5 lymphoma in vitro by sulfoxide-ruthenium compounds and cisplatin detected by flow cytometry. Chem Biol Interact 113:51-63

Carreau A, Kieda C, Grillon C (2011) Nitric oxide modulates the expression of endothelial cell adhesion molecules involved in angiogenesis and leukocyte recruitment. Exp Cell Res 317:29-41

Collet G, Szade K, Nowak W, Klimkiewicz K, El Hafny-Rahbi B, Szczepanek K, Sugiyama D, Weglarczyk K, FoucaultCollet A, Guichard A, Mazan A, Nadim M, Fasani F, Lamerant-Fayel N, Grillon C, Petoud S et al (2016) Endothelial precursor cell-based therapy to target the pathologic angiogenesis and compensate tumor hypoxia. Cancer Lett 370:345-357

Dufraine J, Funahashi Y, Kitajewski J (2008) Notch signaling regulates tumor angiogenesis by diverse mechanisms. Oncogene 27:5132-5137

Greenwald I (1998) LIN-12/Notch signaling: lessons from worms and flies. Genes Dev 12:1751-1762

Groessl M, Reisner E, Hartinger CG, Eichinger R, Semenova O, Timerbaev AR, Jakupec MA, Arion VB, Keppler BK (2007) Structure-activity relationships for NAMI-A-type complexes (HL) trans- $\mathrm{RuCl}_{4} \mathrm{~L}(\mathrm{~S}-\mathrm{dmso})$ ruthenate(III)] ( $\mathrm{L}=$ imidazole, indazole, 1,2,4-triazole, 4-amino-1,2,4triazole, and 1-methyl-1,2,4-triazole): aquation, redox properties, protein binding, and antiproliferative activity. J Med Chem 50:2185-2193

Höckel M, Vaupel P (2001) Tumor hypoxia: definitions and current clinical, biologic, and molecular aspects. J Natl Cancer Inst 93:266-276

Kieda C, Paprocka M, Krawczenko A, Załecki P, Dupuis P, Monsigny M, Radzikowski C, Duś D (2002) New human microvascular endothelial cell lines with specific adhesion molecules phenotypes. Endothel J Endothel 9:247-261

Kieda C, Hafny-Rahbi B, Collet G, Lamerant-Fayel N, Grillon C, Guichard A, Dulak J, Jozkowicz A, Kotlinowski J, Fylaktakidou KC, Vidal A, Auzeloux P, Miot-Noirault E, Beloeil JC, Lehn JM, Nicolau C (2013) Stable tumor vessel normalization with $\mathrm{pO} 2$ increase and endothelial PTEN activation by inositol trispyrophosphate brings novel tumor treatment. J Mol Med 91:883-899

Krebs LT, Xue Y, Norton CR, Shutter JR, Maguire M, Sundberg JP, Gallahan D, Closson V, Kitajewski J, Callahan R, Smith GH, Stark KL, Gridley T (2000) Notch signaling is essential for vascular morphogenesis in mice. Genes Dev 14:1343-1352

Leong KG, Hu X, Li L, Noseda M, Larrivee B, Hull C, Hood L, Wong F, Karsan A (2002) Activated Notch4 inhibits angiogenesis: role of beta 1-integrin activation. Mol Cell Biol 22:2830-2841

Mazuryk O, Kurpiewska K, Lewiński K, Stochel G, Brindell M (2012) Interaction of apo-transferrin with anticancer ruthenium complexes NAMI-A and its reduced form. J Inorg Biochem 116:11-18

Mestroni G, Alessio E, Sava G (1998) New salt of anionic complexes of $\mathrm{Ru}(\mathrm{III})$ as antimetastatic and antineoplastic agents. Int Patent WO 98/00431 
Milner LA, Bigas A (1999) Notch as a mediator of cell fate determination in hematopoiesis: evidence and speculation. Blood 93:2431-2448

Morbidelli L, Donnini S, Filipi S, Messori L, Piccioli F, Sava G, Ziche M (2003) Antiangiogenic properties of selected ruthenium(III) complexes that are nitric oxide scavengers. Br J Cancer 88:1484-1491

Oszajca M, Mrugała B, Brindell M (2016) Aqueous behaviour and reactivity towards nitric oxide of NAMI-A type complexes bearing bulky N-heterocyclic ligands. Submitted to Inorg Chim Acta. doi:10.1016/j.ica.2016.09.032

Paprocka M, Krawczenko A, Dus D, Kantor A, Carreau A, Grillon C, Kieda C (2011) CD133 positive progenitor endothelial cell lines from human cord blood. Cytom Part A 79:594-602

Pintus G, Tadolini B, Posadino AM, Sanna B, Debidda M, Bennardini F, Sava G, Ventura C (2002) Inhibition of the MEK/ERK signaling pathway by the novel antimetastatic agent NAMI-A down regulates c-myc gene expression and endothelial cell proliferation. Eur J Biochem 269:5861-5870

Reisner E, Arion VB, da Silva MFCG, Lichtenecker R, Eichinger A, Keppler BK, Kukushkin VY, Pombeiro AJL
(2004) Tuning of redox potentials for the design of ruthenium anticancer drugs-an electrochemical study of $\left[\text { trans }-\mathrm{RuCl}_{4} \mathrm{~L}(\mathrm{DMSO})\right]^{-}$and $\left[\text {trans }-\mathrm{RuCl}_{4} \mathrm{~L}_{2}\right]^{-}$complexes, where $\mathrm{L}=$ imidazole, 1,2,4-triazole, indazole. Inorg Chem 43:7083-7093

Timerbaev AR, Hartinger CG, Aleksenko SS, Keppler BK (2006) Interactions of antitumor metallodrugs with serum proteins: advances in characterization using modern analytical methodology. Chem Rev 106:2224-2248

Uyttendaele H, Ho J, Rossant J, Kitajewski J (2001) Vascular patterning defects associated with expression of activated Notch4 in embryonic endothelium. Proc Nat Acad Sci USA 98:5643-5648

Vacca A, Bruno M, Boccarelli A, Coluccia M, Ribatti D, Bergamo A, Garbisa S, Sartor S, Sava G (2002) Inhibition of endothelial cell functions and of angiogenesis by the metastasis inhibitor NAMI-A. Br J Cancer 86:993-998

Vaupel P, Mayer A (2007) Hypoxia in cancer: significance and impact on clinical outcome. Cancer Metastasis Rev 26:225-239 